\title{
Myocardial Metabolism and Function in Acutely Ischemic and Hypoxemic Isolated Rat Hearts
}

\author{
M. Samaja ${ }^{1}$, R. Motterlini² ${ }^{2}$ S. Allibardi ${ }^{2}$, S. Casalini ${ }^{1}$, G. Merati ${ }^{1}$, A. Corno ${ }^{3}$, \\ and S. Chierchia ${ }^{2}$ \\ ${ }^{1}$ Department of Biomedical Science and Technology, University of Milano, ${ }^{2}$ Scientific Institute San \\ Raffaele, ${ }^{3}$ Hospital San Donato, Milano, Italy
}

(Received 7 July 1994. accepted in revised form 14 November 1994)

\begin{abstract}
M. Samaja, R. Motterlini, S. Allibardi, S. Casalini, G. Merati, A. Corno, and S. Chierchia. Myocardial Metabolism and Function in Acutely Ischemic and Hypoxemic Isolated Rat Hearts. Journal of Molecular and Cellular Cardiology. (1995) 27, 1213-1218. We tested the hypothesis that residual oxygen supply during acute low-flow ischaemia or hypoxemia is a major regulator of myocardial performance, metabolism and recovery. Rat hearts were exposed for $20 \mathrm{~min}$ to either ischemia (coronary flow reduced to $10 \%$ of baseline). hypoxemia (oxygen content reduced to $10 \%$ baseline) or a "mixed" condition (combined ischaemia and hypoxemia). The oxygen supply (coronary flow $\times$ oxygen content) was matched in all groups ( $n=16$ per group). Hypoxemic hearts had the highest performance (systolic and developed pressures, $\pm \mathrm{dP} / \mathrm{dt} t_{\max }$ and oxygen uptake) and content of IMP and AMP. Ischaemic hearts had the highest content of ATP, phosphocreatine, adenine nucleotides and purines. As flow and/or oxygenation were restored, post-ischemic hearts showed better functional and metabolic recovery than post-hypoxemic ones. "Mixed" hearts were more similar to hypoxemic ones during oxygen shortage but to ischemic ones during recovery. We conclude that as oxygenation is critically limiting, coronary flow is relatively more important than oxygen supply in determining myocardial function, metabolism and recovery, most likely secondary to changes in the metabolism of diffusible substances.
\end{abstract}

KEY WorDs: Ischemia; Hypoxemia; Metabolism; ATP; Phosphocreatine; Adenine nucleotides; Recovery.

\section{Introduction}

Ischemia is characterized by low coronary flow $\left(C F^{1}\right)$ with respect to tissue needs. If metabolic factors only are considered, excluding blood-related phenomena, the ischemic dysfunction is driven by low supply of $\mathrm{O}_{2}\left(\mathrm{QO}_{2}\right)$ and low washout of diffusible substances. These phenomena, although superimposed within a single ischaemic episode, are distinct and involve different metabolic patterns.
Low $\mathrm{QO}_{2}$ impairs mitochondrial function and decreases aerobic ATP production (Connett et al., 1990). Washout of diffusible substances such as adenosine, inosine and hypoxanthine depresses the size of the ATP pool (Gutierrez et al., 1988; Soussi et al., 1993; Bak and Ingwall, 1994). Furthermore, since the ATP level during ischemia may be critical in determining dysfunction during recovery (Haas et al., 1984: Takeo et al., 1988; Ambrosio et al., 1989; Rubin et al.. 1992), both phenomena are

\footnotetext{
${ }^{1}$ List of abbreviations: $\mathrm{CF}$, coronary flow: $\mathrm{CPP}$, coronary perfusion pressure; $+\mathrm{dP} / \mathrm{d} t_{\operatorname{mnx}}$, maximal rate of contraction; $-\mathrm{dP} / \mathrm{d} t_{\max }$, maximal rate of relaxation; EDP, end-diastolic pressure; H, hypoxemia: HR, heart rate; I, ischaemia; MP, inosine monophosphate; LVDP, left-ventricle developed pressure; $M$. "Mixed" case $(\mathrm{I}+\mathrm{H}) ; \mathrm{PCr}$, phosphocreatine; PSP, peak systolic pressure; $\mathrm{QO}_{2}$, supply of $\mathrm{O}_{2}$ i TAN, sum of adenine nucleotides and purines (ATP + ADP + AMP + IMP + adenosine + inosine + hypoxanthine); VO $\mathrm{O}_{2}, \mathrm{O}_{2}$ uptake.

Please address all correspondence to: Dr. Michele Samaja, Università di Milano, Dipartimento di Scienze e Tecnologie Biomediche, Istituto Scientifico San Raffaele, via Olgettina 60, I-20132 Milano, Italy.
} 
potentially involved during reperfusion injury. However, the relative roles of $\mathrm{QO}_{2}$ and washout of diffusible substances is still unclear. Separating these two factors may help in understanding the mechanisms underlying ischemic heart disease. myocardial preconditioning and endogenous protection against ischemia.

To gain a better insight into these mechanisms, we recently developed an experimental approach suitable for measurement of the separate eflects of reduced $\mathrm{QO}_{2}$ and reduced $\mathrm{CF}$ (Samaja et al., 1994a). For this purpose, hearts were exposed to low-flow ischemia (I) or hypoxemia $(\mathrm{H})$ matched for $\mathrm{QO}_{2}$ by reducing either $\mathrm{CF}$ or $\mathrm{PO}_{2}$, respectively, to $10 \%$ of a reference baseline condition. Care was taken to obtain baseline conditions as similar as possible to the in vivo condition and to exert full control of $\mathrm{CF}$ and $\mathrm{PO}_{2}$. Therefore. $\mathrm{QO}_{2}=\mathrm{CF} \times \mathrm{PO}_{2} \times\left(\mathrm{O}_{2}\right.$ solubility coefficient). This approach is also suitable to assess what are the major regulators of myocardial performance and metabolism during acute low-flow ischemia or hypoxemia. In fact, if performance is limited by residual $\mathrm{QO}_{2}$, then a given decrease of $\mathrm{QO}_{2}$ would produce the same effects regardless of what is reduced, $\mathrm{CF}$ or $\mathrm{PO}_{2}$. On the contrary, if washout of diffusible catabolites is more critical than $\mathrm{QO}_{2}$, then $\mathrm{I}$ and $\mathrm{H}$ would induce different metabolic and functional responses. We show that the responses to I and $\mathrm{H}$ are different. To better characterize these differences, we designed a "mixed" group (M), where I and $\mathrm{H}$ are applied simultaneously at the same $\mathrm{QO}_{2}$. For most parameters, $M$ hearts do not rank between I and $\mathrm{H}$ but rather resemble either I or $\mathrm{H}$. Thus, some of the features normally occurring during low-flow ischaemia seem linked to $\mathrm{QO}_{2}$, while others are more strictly dependent on $\mathrm{CF}$.

\section{Materials and Methods}

Ad libitum-fed Sprague-Dawley male rats (weight $250-280 \mathrm{~g}$ ) were anesthetized by i.p. heparinized sodium thiopental $(10 \mathrm{mg} / 100 \mathrm{~g}$ body weight). Hearts were perfused in a Langendorff mode through the aorta with Krebs-Henseleit buffer containing $2.0 \mathrm{~mm}$ free $\mathrm{Ca}^{2+}$ and $16.6 \mathrm{~mm}$ glucose $(\mathrm{pH}$ $7.4,37^{\circ} \mathrm{C}$ ). The medium was equilibrated at the desired $\mathrm{PO}_{2}$ in membane oxygenators (Dideco, Mirandola, Italy). $\mathrm{PCO}_{2}$ was $43 \mathrm{mmHg}$. A pump delivered the medium at desired flows to a filter ( $8 \mu \mathrm{m}$ pore size, $47 \mathrm{~mm}$ diameter, Nuclepore Corp., Pleasanton, CA, USA), a preheater and the aortic cannula.

We measured the coronary perfusion pressure
(CPP), end diastolic pressure (EDP), peak systolic pressure (PSP). left ventricle-developed pressure (LVDP), heart rate (HR), maximal rate of contraction $\left(+\mathrm{dP} / \mathrm{d} t_{\max }\right)$ and maximal rate of relaxation $\left(-\mathrm{dp} / \mathrm{d} t_{\text {max }}\right)$. The effluent was analysed for venous $\mathrm{PO}_{2} \quad\left(\mathrm{P}_{\mathrm{v}} \mathrm{O}_{2}\right)$ using an oxygen electrode (YSI mod.5300 Oxygen Monitor, Yellow Springs Inc., $\mathrm{OH}, \mathrm{USA})$. The $\mathrm{O}_{2}$ uptake $\left(\mathrm{VO}_{2}\right)$ was calculated from actual $\mathrm{P}_{v} \mathrm{O}_{2}, \mathrm{P}_{41} \mathrm{O}_{2}$ and $\mathrm{CF}^{\prime}$. Vascular resistance was calculated as (CPP-EDP)/CF/(ventricle weight) (Cunningham et al., 1990).

Hearts were stabilized for $30 \mathrm{~min}$ at $\mathrm{CF}=15 \mathrm{ml} /$ $\min$ and $\mathrm{PO}_{2}=670 \mathrm{mmHg} \quad\left(Q_{2}=14.1 \mu\right.$ moles $/$ $\mathrm{min})$, with the ventricular balloon volume adjusted to achieve EDP $=10 \pm 1 \mathrm{mmHg}$ and kept constant throughout. I and $\mathrm{H}$ were applied by reducing either $\mathrm{CF}$ to $1.5 \mathrm{ml} / \mathrm{min}$ or $\mathrm{PO}_{2}$ to $67 \mathrm{mmHg}$. In the "mixed" case $(\mathrm{M}), \mathrm{CF}=7.2 \mathrm{ml} / \mathrm{min}$ and $\mathrm{PO}_{2}=$ $140 \mathrm{mmHg}$. For all three groups, $\mathrm{QO}_{2}=$ $1.41 \mu \mathrm{moles} / \mathrm{min}$ for $20 \mathrm{~min}$. At end of I, M or $\mathrm{H}$, hearts were reperfused and/or reoxygenated for 20 min.

Baseline measurements were taken at the end of stabilization just before the beginning of $\mathrm{O}_{2}$ shortage. Other measurements were taken at the end of the $20 \mathrm{~min}$ periods of $\mathrm{O}_{2}$ shortage and recovery. Part of the hearts were freeze-clamped with liquid nitrogen for perchloric acid extraction and tissue dry weight determination at end of baseline, $\mathrm{O}_{2}$ shortage and recovery. High-pressure liquid chromatography was performed to assay ATP, ADP. AMP, IMP, adenosine, inosine and hypoxanthine (Motterlini et al.. 1992). Xanthine and uric acid were never detected by this method.

Data are expressed as mean \pm s.E. ANOVA test was performed and if significant, the Fisher's protected least significant difference test was performed to compare the various groups (significance level was $P=0.05$, two-tailed).

\section{Results}

In 90 min control experiments at full $\mathrm{QO}_{2}$ (not shown), the changes of EDP, LVDP and CPP were less than $+1,-5$ and $+5 \mathrm{mmHg}$, respectively. As expected, when $\mathrm{QO}_{2}$ was reduced to $10 \%$ of the baseline value, both performance and metabolism were severely depressed (Table 1). However, the dysfunction was critically dependent on how $\mathrm{QO}_{2}$ was shortened. Diastolic contracture ranked $\mathrm{H}>\mathrm{M}>\mathrm{I}$, but LVDP, LVDP $\times \mathrm{HR},+\mathrm{dP} / \mathrm{d} t_{\max }$ and $-\mathrm{dP} / \mathrm{d} t_{\max }$ ranked $\mathrm{H}=\mathrm{M}>\mathrm{I}$. Although $\mathrm{VO}_{2}$ and $\mathrm{HR}$ were comparable in all groups $(\mathrm{H}=\mathrm{M}=\mathrm{I}), \mathrm{P}_{\mathrm{v}} \mathrm{O}_{2}$ was much less in $\mathrm{H}$ than $\mathrm{I}$ hearts. The contents of 
Table 1 Data obtained at end of baseline $\left(\mathrm{O}_{2}\right.$ supply $\left.=14.1 \mu \mathrm{moles} / \mathrm{min}\right)$ and after $20 \mathrm{~min}$ of $\mathrm{O}_{2}$ shortage (ischaemia, "mixed" or hypoxemia) with $\mathrm{O}_{2}$ supply $=1.41 \mu \mathrm{moles} / \mathrm{min}$. Results of ANOVA and Fisher's lests $(P<0.05): *$. Mixed $v$ Ischemia: $\dagger$. Hypoxemia $v$ Mixed: $\ddagger$. Hypoxemia $v$ Ischemia

\begin{tabular}{|c|c|c|c|c|}
\hline & Baseline & Ischemia & Mixed & Hypoxemia \\
\hline$n$ & 51 & 16 & 17 & 16 \\
\hline Flow, $\mathrm{ml} / \mathrm{min}$ & 15 & 1.5 & 7.2 & 15 \\
\hline $\mathrm{P}_{\mathrm{i}} \mathrm{O}_{2}, \mathrm{mmHg}$ & 670 & 670 & 140 & 67 \\
\hline $\mathrm{OO}_{2}, \mu$ moles $/ \mathrm{min}$ & 14.1 & 1.41 & 1.41 & 1.41 \\
\hline $\mathrm{P}_{4} \mathrm{O}_{2}, \mathrm{mmHg}$ & $335 \pm 31$ & $100 \pm 14$ & $10 \pm 1^{*}$ & $4 \pm 1 \ddagger$ \\
\hline $\mathrm{VO}_{2}, \mu \mathrm{moles} / \mathrm{min}$ & $6.97 \pm 0.61$ & $1.20 \pm 0.03$ & $1.33 \pm 0.01^{*}$ & $1.29 \pm 0.02$ \\
\hline $\mathrm{HR}^{-} \min ^{-1}$ & $270 \pm 8$ & $178 \pm 12$ & $176 \pm 12$ & $173 \pm 15$ \\
\hline $\mathrm{EDP}, \mathrm{mmHg}$ & $9.3 \pm 0.6$ & $5.3 \pm 0.4$ & $9.7 \pm 1.7$ & $25.6 \pm 3.4 \dagger \ddagger$ \\
\hline LVDP, $\mathrm{mmHg}$ & $150 \pm 5$ & $31 \pm 4$ & $49 \pm 3^{*}$ & $50 \pm 5 \ddagger$ \\
\hline $\begin{array}{l}\mathrm{LVDP} \times \mathrm{HR} \\
\mathrm{mmHg} \times 10^{3} / \mathrm{min}\end{array}$ & $40.6 \pm 1.9$ & $5.2 \pm 0.5$ & $8.4 \pm 0.5^{*}$ & $7.9 \pm 0.6 \ddagger$ \\
\hline$+\mathrm{dP} / \mathrm{d} t_{\max } . \mathrm{mmHg} / \mathrm{s}$ & $4955 \pm 214$ & $1181 \pm 96$ & $2024 \pm 88^{*}$ & $2037 \pm 139 \ddagger$ \\
\hline$-\mathrm{dP} / \mathrm{d} t_{\text {mix. }} . \mathrm{mmHg} / \mathrm{s}$ & $3331 \pm 130$ & $730 \pm 61$ & $1074 \pm 53^{*}$ & $1123 \pm 100 \ddagger$ \\
\hline $\mathrm{CPP}, \mathrm{mmHg}$ & $75 \pm 4$ & $9 \pm 1$ & $33 \pm 1^{*}$ & $70 \pm 4+7$ \\
\hline $\begin{array}{l}\text { Resistance, } \\
\mathrm{mmHg} \times \mathrm{min} / \mathrm{ml} / \mathrm{g}\end{array}$ & $4.36 \pm 0.29$ & $2.15 \pm 0.70$ & $3.30 \pm 0.24$ & $2.95 \pm 0.33$ \\
\hline ATP. $\mu$ moles $/ g \mathrm{~d} w$ & $21.9 \pm 1.6$ & $20.4 \pm 1.0$ & $18.5 \pm 1.3$ & $13.2 \pm 0.8 \dagger \ddagger$ \\
\hline IMP. $\mu$ moles $/ \mathrm{g} \mathrm{dw}$ & $0.04 \pm 0.04$ & $0.15 \pm 0.05$ & $0.31 \pm 0.04^{*}$ & $0.54 \pm 0.06 t+$ \\
\hline $\mathrm{PCr}, \mu$ moles/g dw & $26.4 \pm 2.4$ & $21.9 \pm 1.9$ & $15.6 \pm 1.4^{*}$ & $10.4 \pm 1.1 \dagger \ddagger$ \\
\hline $\mathrm{TAN}, \mu$ moles/g dw & $33.9 \pm 2.7$ & $33.5 \pm 1.5$ & $33.6 \pm 1.9$ & $28.6 \pm 1.5 t \dagger$ \\
\hline
\end{tabular}
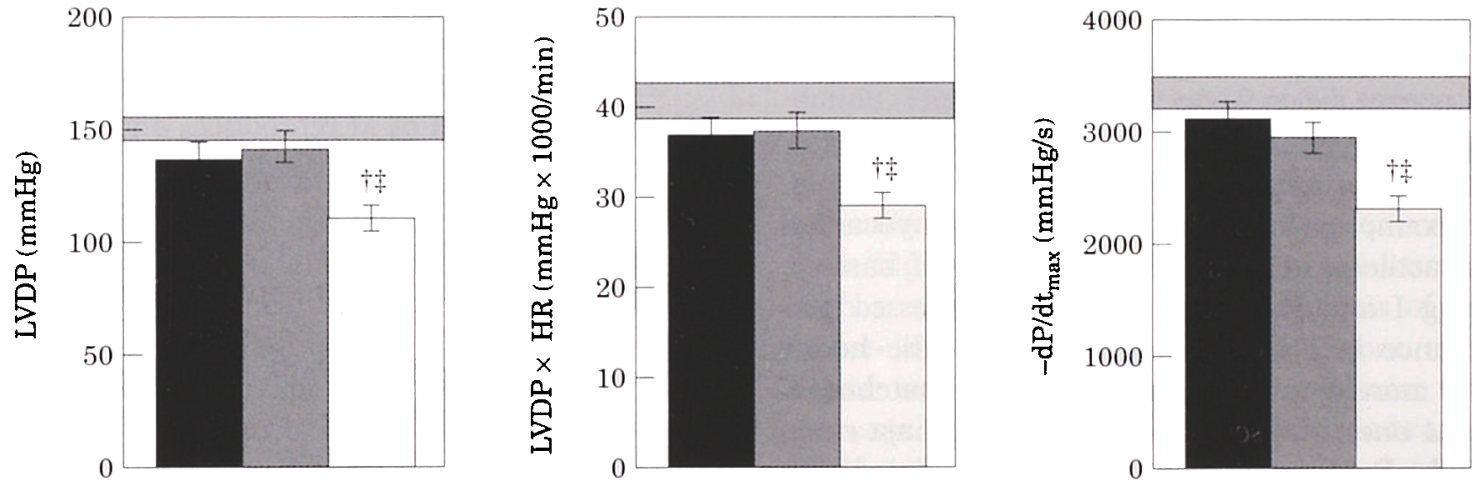

Figure 1 Recovery of mechanical performance 20 min after restoration of flow and/or oxygenation. Results of ANOVA and Fisher's tests $(P<0.05):{ }^{*}$. Mixed (圆) v Ischemia ( $\square$ ); $\uparrow$. Hypoxemia $(\square) v$ Mixed; $\ddagger$. Hypoxemia $v$ Ischemia. The horizontal strip represents the baseline values $( \pm$ s.E.).

$\mathrm{PCr}$ and ATP were not significantly different from baseline in I hearts, but significantly less in $\mathrm{H}$ hearts. The contents of IMP and of the sum of adenine nucleotides and purines (TAN. $\mathrm{ATP}+\mathrm{ADP}+\mathrm{AMP}+\mathrm{IMP}+$ adenosine, +inosine + hypoxantine) ranked $\mathrm{H}>\mathrm{M}>\mathrm{I}$ and $\mathrm{H}<\mathrm{M}=\mathrm{I}$, respectively.

Figure 1 shows that the recovery of performance following reoxygenation after $\mathrm{H}$ is less than that following reperfusion after I. $M$ hearts behave like I hearts $(\mathrm{H}<\mathrm{M}=\mathrm{I})$. Both ATP and TAN at recovery ranked $\mathrm{H}<\mathrm{M}=\mathrm{I}$ (Fig. 2). Phosphocreatine was the same in all groups.

\section{Discussion}

The $\mathrm{QO}_{2}$ during baseline compares well with the $\mathrm{QO}_{2}$ of in vivo hearts $(8.5-10.1 \mu \mathrm{moles} / \mathrm{min} / \mathrm{g}$, assuming $\mathrm{CF}=70-85 \mathrm{ml} / 100 \mathrm{~g} / \mathrm{min},[\mathrm{Hb}]=15.5 \mathrm{~g} / \mathrm{dl} .98 \%$ $\mathrm{O}_{2}$-saturated at $\mathrm{PO}_{2}=100 \mathrm{mmHg}$ ). The relatively high glucose concentration saturates the glucose transport system (Zweier and Jacobus, 1987) and prevents glucose shortage during I. Indeed, under the lowest $\mathrm{CF}$ condition in this study, the glucose supply $(190 \mu \mathrm{mol} / \mathrm{min} / \mathrm{g}$ dry weight $)$ exceeds by one order of magnitude the maximal glucose utilization by anoxic Langendorff-perfused isolated rat 

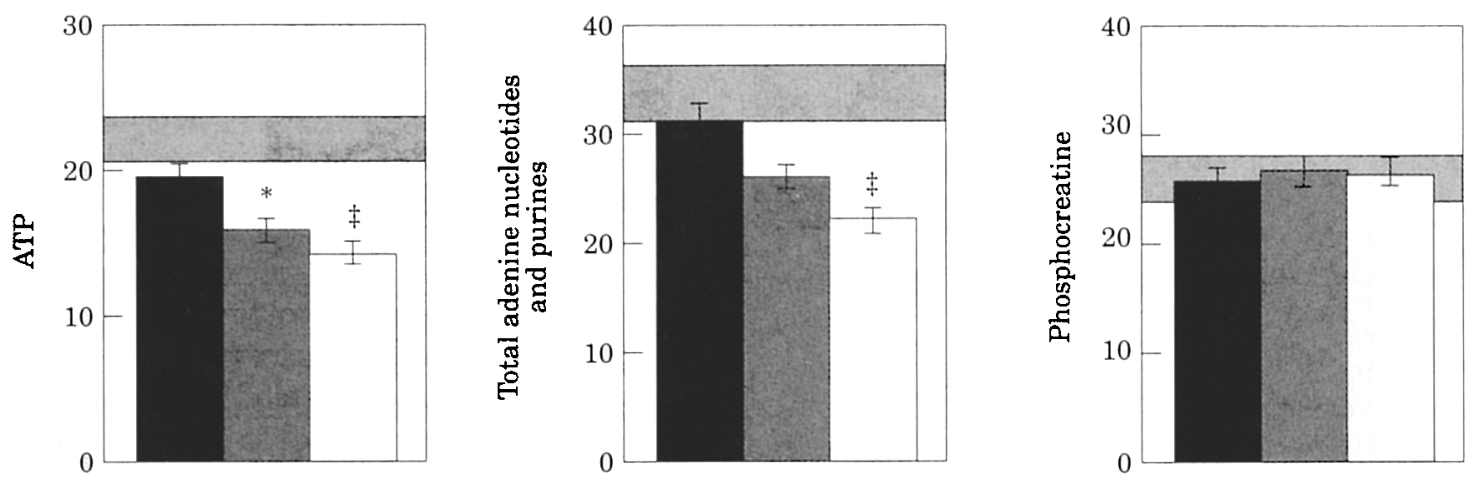

Figure 2 Recovery of metabolic parameters $20 \mathrm{~min}$ after restoration of flow and/or oxygenation. Concentrations as $\mu$ moles/g d.w. Results of ANOVA and Fisher's tests $(P<0.05)$ : *, Mixed (圈) v Ischemia ( $\square$ ); $\neq$. Hypoxemia ( $\square$ ) $v$ Ischemia. The horizontal strip represents the baseline values $( \pm$ S.E. $)$.

hearts $[14 \mu \mathrm{mol} / \mathrm{min} / \mathrm{g}$ dry weight (Rovetto et al., 1975)]. Hyperglycemia does not have any significant effect in our model because the glycolytic rate is regulated by enzyme activity rather than intracellular glucose (Kobayashi and Neely, 1979) and there is no competition between glucose and other substrates.

\section{Performance during $\mathrm{O}_{2}$ shortage}

The dysfunction was different during $\mathrm{I}, \mathrm{M}$ or $\mathrm{H}$. For example, LVDP $\times \mathrm{HR}$, an index of myocardial contractile work, was $13 \%$ and $21 \%$ of baseline during $\mathrm{I}$ and $\mathrm{H}$, respectively. The depressed performance in $\mathrm{I}$ hearts indicates that these hearts were more downregulated than $\mathrm{QO}_{2}$-matched $\mathrm{H}$ and $M$ ones as discussed elsewhere (Samaja et al., 1994b). Downregulation during I is associated with low washout of lactate, intracellular lactate retention, lactate-induced acidosis and hence depression of glycolysis (Rovetto et al., 1975; Matthews et al., 1986; Zhou et al., 1991).

In our model, CPP is mainly determined by different CF's under the various experimental conditions, thus CPP ranked $\mathrm{H}>\mathrm{M}>\mathrm{I}$. Therefore, we can not exclude perfusion heterogeneities especially during I (Hogan et al., 1993). However, resistance did not vary significantly among the various groups $(\mathrm{H}=\mathrm{M}=\mathrm{I})$ indicating that myocardial perfusion remained essentially constant. This also suggests that the differences observed here are primarily due to metabolic phenomena rather than microcirculatory adjustments.

$\mathrm{P}_{\mathrm{v}} \mathrm{O}_{2}$ was less in $\mathrm{H}$ than $\mathrm{I}$ hearts, even at the same $\mathrm{QO}_{2}$, according to observations obtained by others in skeletal muscle (Hogan et al., 1992; Dodd et al., 1993). It is difficult to assess whether this phenomenon is due to non-uniform perfusion secondary to low CPP in I hearts or to lactate-driven downregulation. In both cases, however, residual $\mathrm{QO}_{2}$ does not appear to be an adequate energy reserve as shown by the essentially unchanged $\mathrm{VO}_{2}$. We already demonstrated that, as $\mathrm{QO}_{2}$ is reduced to $1.41 \mu \mathrm{moles} / \mathrm{min}$. ATP from anaerobic glycolysis is needed to sustain adequate ATP turnover during both I and H (Samaja et al., 1.994b).

The development of diastolic contracture during $\mathrm{H}$ but not during $\mathrm{I}$ or $\mathrm{M}$ reproduces and reinforces previously reported data (Wexler et al., 1986). Despite substantial differences in study design, the explanations for these features are the same: the development of contracture during $\mathrm{H}$ may be secondary to impaired resequestration of $\mathrm{Ca}^{2+}$ by the sarcoplasmic reticulum while the increased ventricle distensibility during I results from collapsed vasculature and development of acidosis, that decreases the myofibrils sensitivity to $\mathrm{Ca}^{2+}$

\section{Metabolism during $\mathrm{O}_{2}$ shortage}

Measuring the ATP content is limiting with respect to the ATP turnover through creatine kinase but the steady-state content of ATP and PCr may still reflect the overall balance between metabolic supply and utilization because of the rapid turnover rate of their pools (Zweier and Jacobus, 1987). The total ADP content in freeze-clamped tissue is not a valuable index of its activity because $A D P$ is highly compartmentalized in the cell and the free ADP content has to be considered (Humphrey et al., 1990).

In I hearts, the contents of PCr and ATP are relatively higher than in $\mathrm{H}$ hearts. This reflects the lower performance and energy demand of I 
compared to H. The lower IMP, an index of metabolic derangement during $\mathrm{O}_{2}$ shortage (Achterberg et al., 1988), and higher TAN content during I also reflect the low energy demand in I hearts. This situation allows better ATP/ADP coupling and consequently less degradation of adenylic compounds beyond AMP. On the other hand, in $\mathrm{H}$ hearts, high lactate washout releases the inhibition due to acidosis. This leads to high energy demand (Samaja et al., 1994b), reduced ATP/ADP coupling and increased amount of adenine nucleotides degraded beyond AMP. These substances are virtually lost for the ATP pool because some of the degradation reactions, especially that catalysed by $5^{\prime}$-nucleotidase (Bak and Ingwall, 1994), are irreversible (Achterberg et al., 1988). Furthermore, high CF during $\mathrm{H}$ removes adenosine, inosine and hypoxanthine (Gutierrez et al., 1988; Soussi et al., 1993; Bak and Ingwall, 1994), contributing to a decrease in TAN content. Failure to detect xanthine and urate in tissue extracts may reflect high xanthine oxidoreductase activity in rat hearts (de Jong $e t$ al., 1990) with associated leakage of these substances.

\section{Recovery}

The finding that $\mathrm{H}$ is more deleterious than $\mathrm{I}$ is in agreement with our previous data (Corno et al., Samaja et al., 1994a) and the above considerations. In fact, dysfunction during recovery may be intended as a biological assay of the ability of the heart to restore its high-energy phosphate pool (Bak and Ingwall, 1994). Therefore, better recovery from I than from $\mathrm{H}$ reflects better maintenance of the ATP pool during I than during $\mathrm{H}$. In our model, purine salvage is the only way for the heart to restore the ATP pool, because de novo purine biosynthesis is slow even when accelerated by $\mathrm{O}_{2}$ shortage (Zimmer et al., 1973). Phosphocreatine was the same in all groups, because neither creatine nor phosphocreatine are diffusible substances (Savabi, 1988), and thus they do not leak under highflow conditions like diffusible adenine nucleotides and purines.

Why are $\mathrm{M}$ hearts more similar to $\mathrm{H}$ ones during the $\mathrm{O}_{2}$ shortage and to $\mathrm{I}$ ones during the reperfusion? Clearly some parameters are more strictly dependent on $\mathrm{PO}_{2}$ while others depend more strongly on CF. For example, recovery of performance appears to follow a pattern similar to that of ATP and TAN contents during $\mathrm{O}_{2}$ shortage $(\mathrm{H}<\mathrm{M}=\mathrm{I})$. Thus recovery may depend on the preservation of the adenine nucleotides pool, which is consistent with other observations (Haas et al., 1984; Takeo et al.,
1988; Ambrosio et al., 1989; Rubin et al., 1992). As a corollary, since maintenance of the ATP pool depends on the washout of diffusible adenosine, hypoxanthine and inosine, residual CF during lowflow ischemia may appear critical to determine recovery. However, ATP content is reduced in $M$ hearts at the end of recovery despite excellent function possibly indicating that factors other than adenine nucleotides metabolism may be involved in these mechanisms.

Although we fully agree with LH Opie that the concept of critical levels of ATP is now defunct (Opie, 1992). low ATP level is necessarily associated with high amounts of diffusible adenine nucleotides and purines. Therefore, we propose to extend that statement to include flow: if a low ATP situation is associated with high flow, the combination of both factors may ultimately impair the capability of hearts to recover ATP at reperfusion after acute ischemia because of precursors loss.

\section{Conclusion}

Ischemia and hypoxemia elicit different metabolic and mechanical responses at equal levels $\mathrm{O}_{2}$ limitation. Thus, factors different from $\mathrm{QO}_{2}$ presumably regulate myocardial function and metabolism during ischemia and recovery. The differences between ischemia and hypoxemia appear related to coronary flow: high flows during hypoxemia are associated with greater ATP requirements and loss of membrane-diffusible substances. These factors, as well as the energy imbalance during ischemia, which increase the intracellular level of membrane-diffusible metabolites, need to be investigated as factors responsible for myocardial dysfunction during recovery from acute ischemia.

\section{Acknowledgements}

Supported by the Fondazione San Romanello del Monte Tabor, Milano, and the Target Project BTBS, Roma, Italy.

\section{References}

ACHTERBerg PW, NiEukoop AS, Schoutsen B, DE JoNg JW. 1988. Different ATP catabolism in reperfused adult and newborn rat hearts. Am J Physiol 254: H1091-H1098.

Ambrosio G, Jacobus WE, Mitchell MC, LITT MR, BeckRR LC. 1989. Effects of ATP precursors on ATP and free ADP content and functional recovery of postischaemic hearts. Am J Physiol 256: H560-H566. 
BAK MI, INGWALL JS, 1994. Acidosis during ischemia promotes adenosine triphosphate resynthesis in postischaemic rat heart. J Clin Invest 93: 40-49.

Connett RJ. Honig CR, Gayeski TEJ, Brooks GA, 1990. Defining hypoxia: a systems view of $\mathrm{VO}_{2}$, glycolysis. energetics, and intracellular $\mathrm{PO}_{2}$. J Appl Plysiol 68: $833-842$.

Corno A, Motterlini R, Brenna L, Santoro F, Samaja $M$, 1993. Ischaemia/reperfusion in the posthypoxaemic re-oxygenated myocardium: haemodynamic study in the isolated perfused rat heart. Perfusion 8: 113-118.

Cunningham MJ, Apstein CS, Weinberg EO. Vogel WM. LORRELL BH, 1990. Influence of glucose and Insulin on the exaggerated diastolic and systolic dysfunction of hypertrophied rat hearts during hypoxia. Circ Res 66: $406-415$.

de JoNG JW, van der MEer P, Nieukoop AS, Huizer T, Stroeve RJ, Bose E, 1990. Xanthine oxidoreductase activity in perfused hearts of various species, including humans. Circ Res 67: 770-773.

Dodd SL, Powers SK, Brooks E. Crawford MP, 1993. Effects of reduced $\mathrm{O}_{2}$ delivery with anemia, hypoxia, or ischaemia on peak $\mathrm{VO}_{2}$ and force in skeletal muscle. J Appl Physiol 74: 186-191.

Gutierrez G. Pohl RJ, ANDry JM, Strong R, Narayana $P, 1988$. Bioenergetics of rabbit skeletal muscle during hypoxemia and ischaemia. J Appl Physiol 65: 608-616.

Haas GS, Deboer LWV, O'Keefe DDO, Bodenhamer RM. GefFin GA, Drop LJ. Teplick RS, Daggett WM, 1984. Reduction of postischemic myocardial dysfunction by substrate repletion during reperfusion. Circulation 70 : 165-174.

Hogan MC, Nioka S, Brechue WF, Chance B, 1992. A ${ }^{31} \mathrm{P}$ NMR study of tissue respiration in working dog muscle during reduced $\mathrm{O}_{2}$ delivery conditions. $J$ Appl Physiol 73: 1662-1670.

Hogan MC, Bebout DE, Wagner PD, 1993. Effect of blood flow reduction on maximal $\mathrm{O}_{2}$ uptake in canine gastrocnemius muscle in situ. J Appl Physiol 74: 17421747.

HuMPHREY SM, BuCKMAN JE, Holliss DG, 1990. Subcellular distribution of energy metabolites in the preischaemic and post-ischaemic perfused working rat heart. Eur J Biochem 191: 755-759.

Kobayashi K, NeELY JR, 1979. Control of maximum rate of glycolysis in rat cardiac muscle. Circ Res 44: 166-175.
Matthews PM. Taylor DJ, Radda GK. 1986. Biochemical mechanisms of acute contracture failure in the hypoxic rat heart. Cardiovascular Res 20: 13-19.

Motterlini R. Samaja M. Tarantola M. Micheletti R, BIANCHI G, 1992. Functional and metabolic effects of propionyl-L-carnitine in the isolated perfused hypertrophied rat heart. Mol Cell Biochem 116: 139-145.

OPIE LH, 1992. Cardiac metabolism - emergence, decline and resurgence. Part I. Cardiovasc Res 26: 721-733.

RovetTo MJ. Lamberton WF. NeELy JR, 1975. Mechanisms of glycolytic inhibition in ischemic rat hearts. Circ Res 37: 742-751.

Rubin BB. Liauw S. Titrley J. Romaschin AD. Walker PM, 1992. Prolonged adenine nucleotide resynthesis and reperfusion injury in postischaemic skeletal muscle. Am J Physiol 262: H1538-H1547.

Samaja M, Motterlini R, Santoro F, Dell'Antonio G, Corno A, 1994a. Oxidative injury in reoxygenated and reperfused hearts. Free Rad Biol Med 16: 255-262.

Samaja M. Casalini S, Allibardi S. Corno A, Chierchia SL, 1994b. Regulation of bioenergetics in $\mathrm{O}_{2}$-limited isolated rat hearts. J Appl Physiol 77: 2530-2536.

SavaBi F, 1988. Free creatine available to the creatine phosphate energy shuttle in isolated rat atria. Proc Natl Acad Sci USA 85: 7476-7480.

SOUSSI B, LagerWall K, IDSTROM JP, Schersten T, 1993. Purine metabolic pathways in rat hindlimb perfusion model during ischemia and reperfusion. Am J Physiol 265: H1074-H1081.

Takeo S. Tanonaka K, Miyake K, Imago M, 1988. Adenine nucleotides metabolites are beneficial for recovery of cardiac contractile force after hypoxia. $/ \mathrm{Mol}$ Cell Cardiol 20: 187-199.

WEXLER LF, WEINBERg EO, INGWALL JS. APSTEIN CS, 1986. Acute alterations in diastolic left ventricular chamber distensibility: mechanistic differences between hypoxemia and ischaemia in isolated perfused rabbit and rat hearts. Circ Res 59: 515-528.

Zhou HZ, Malhotra D, Shapiro JI, 1991. Contractile dysfunction during metabolic acidosis: role of impaired energy metabolism. Am J Physiol 261: H1481-H1486.

Zimmer HG, Trendelenburg C, Kammermeier H, Gerlach $\mathrm{E}, 1973$. De novo synthesis of myocardial adenine nucleotides in the rat. Circ Res 32: 635-642.

ZWEIER JL, JACOBUS WE, 1987. Substrate-induced alterations of high energy phosphate metabolism and contractile function in the perfused heart. $J$ Biol Chem 262: 8015-8021. 